\title{
Molecular pathology of sarcomas: concepts and clinical implications
}

\author{
Judith V. M. G. Bovée • Pancras C. W. Hogendoorn
}

Received: 29 June 2009 /Revised: 18 August 2009 /Accepted: 24 August 2009 /Published online: 29 September 2009

(C) The Author(s) 2009. This article is published with open access at Springerlink.com

\begin{abstract}
The molecular genetic changes that have been described in sarcomas over the past era have aided our understanding of their pathogenesis. The majority of sarcomas carry nonspecific genetic changes within a background of a complex karyotype. These constitute the challenges in sarcoma research for unraveling a putative multistep genetic model, such as for chondrosarcoma, and finding targets for therapeutic strategies. Approximately $15-20 \%$ of mesenchymal tumors carry a specific translocation within a relatively simple karyotype. The resulting fusion products act either as transcription factors upregulating genes responsible for tumor growth, as for instance in Ewing sarcoma, or translocate a highly active promoter in front of an oncogene driving tumor formation, as for instance in aneurysmal bone cyst. In addition, a small subset of mesenchymal tumors have specific somatic mutations driving oncogenesis. The specific genetic changes unraveled so far had great impact on the classification of bone and soft tissue tumors. In addition, these changes can assist the pathologist in the differential diagnosis of some of these entities, especially within the groups of small blue round cell tumors and spindle cell tumors, if performed in specialized centers. While a putative association between certain fusion products and outcome is still under debate, the role of predicting response of targeted therapy has been well established for KIT and PDGFRA mutations in gastrointestinal stromal tumors.
\end{abstract}

Keywords Bone neoplasm - Soft tissue tumours · Cytogenetics $\cdot$ Molecular pathology $\cdot$ Diagnostics

J. V. M. G. Bovée • P. C. W. Hogendoorn $(\varangle)$

Department of Pathology, Leiden University Medical Center, P.O. Box 9600, L1-Q, 2300 RC Leiden, The Netherlands e-mail: p.c.w.hogendoorn@lumc.nl

\section{Introduction}

More and more knowledge has become available aiding our understanding of the genetic background of cancer. Chromosomal translocations or gene mutations can give the cells in which they arise a growth advantage, ultimately leading to cancer. For bone and soft tissue tumors, an increasing amount of tumor-specific genetic data has become available. Approximately $15-20 \%$ of mesenchymal tumors carry a specific translocation [1] and have relatively simple karyotypes. These translocations are restricted to specific tumor types; in Ewing sarcoma, synovial sarcoma, and myxoid liposarcoma up to $90-95 \%$ of the tumors carry a tumor type-specific translocation. In addition, some tumors carry specific somatic gene mutations (e.g., KIT or PDGFRA mutations in gastrointestinal stromal tumors). In contrast, in the more frequent sarcomas such as osteosarcoma, chondrosarcoma, leiomyosarcoma, or high-grade pleomorphic sarcoma, more complex karyotypes are found with numerous gains and losses, without specific genetic alterations [2].

These molecular data help us to understand the pathogenesis of sarcomas. Moreover, they constitute the basis of the 2002 WHO classification of bone and soft tissue tumors, integrating morphology with genetics [3, 4]. Tumor-specific molecular changes have found their way in daily clinical practice as molecular diagnostic tools to assist the pathologist in diagnosing these lesions, but may also serve as markers to detect minimal residual disease and to predict clinical outcome, although the latter is still somewhat controversial. Finally, our increasing knowledge of the genetic background of sarcomas, including the ones without specific genetic changes, will hopefully enable the development of more types of targeted therapeutic strategies. 


\section{Clues about sarcoma pathogenesis}

Sarcomas with specific reciprocal translocations

For translocation-derived sarcomas, such as Ewing sarcoma, the occurrence of the translocation is considered a very early step in tumorigenesis [5]. In many of the translocations in sarcomas, the EWSR1 or the FUS gene is involved. These promiscuous genes are strongly homologous and encode RNA-binding proteins. Most probably, EWSR1 and FUS have a similar effect when they are involved in a chromosomal translocation. The type of DNA-binding domain originating from the fusion partner probably determines the tumor type that is induced by the translocation.

These hybrid oncoproteins subsequently act as aberrant transcription factors dysregulating gene expression patterns initiating tumor formation. Target genes of the EWSR1ETS fusion products were shown to stimulate cell proliferation (upregulation of PDGF-C, CCDN1, $c-M Y C$ ), evade growth inhibition (downregulation of cyclin-dependent kinase inhibitors and TGF-beta receptor type II), escape from senescence (upregulation of hTERT), escape from apoptosis (repression of IGFBP-3 promoter), induce angiogenesis (VEGF), invasion and metastases (MMPs) [6].

Alternative to aberrant transcription factor activity of fusion products, some other mechanisms of translocationbased tumorigenesis have been described. One of the genes involved in a translocation can be placed under control of the other gene involved in the translocation, which usually leads to over expression. The growth factor PDGFB is placed under control of the COL1A1 promoter in the COL1A1-PDGFB fusion in dermatofibrosarcoma protuberans [7]. This leads to autocrine stimulation and tumor cell proliferation through the PDGF receptor [7, 8]. Similarly, in aneurysmal bone cyst, many different translocations have been described [9, 10], all resulting in oncogenic activation of the USP6 (TRE2 and TRE17) gene on chromosome $17 \mathrm{p} 13$ by placing it under transcriptional control of other, highly active promoters [11]. The mechanism by which upregulation of USP6, involved in actin remodeling [12], causes $\mathrm{ABC}$ formation is so far unknown. Finally, in congenital fibrosarcoma, the ETV6NTRK3 fusion product represents a chimeric tyrosine kinase in itself leading to constitutively active Ras/MAPK mitogenic pathway and PI3K/Akt pathway-mediated cell survival [13].

Sarcomas with specific somatic mutations

In addition, some mesenchymal tumors carry specific somatic mutations that upon their discovery elucidated the pathogenesis of these tumors. For instance, KIT mutations in GIST revealed its relation with the interstitial cells of Cajal. Another example is fibrous dysplasia, a benign fibro-osseous lesion in the medulla of the bone. Polyostotic fibrous dysplasia can be associated with endocrine abnormalities and cafe au lait pigmentation in nonhereditary Mc Cune Albright Syndrome (Online Mendelian inheritance in man NCBI number MIM 174800). Fibrous dysplasia has for long been regarded a nonneoplastic process. Its neoplastic nature was suggested by the occurrence of clonal chromosomal abnormalities found in cytogenetic studies [14]. Fibrous dysplasia is characterized by activating mutations in the Gs alpha (GNAS1) gene localized on chromosome 20q12-q13.3, encoding the alpha subunit of the stimulatory guanine nucleotide-binding protein (G-protein) [15]. G-proteins couple extracellular receptors to intracellular effector enzymes and ion channels, mediating the cellular response to an external stimulus. The identification of GNAS1 mutations also in Mc Cune Albright syndrome (postzygotic) and nonskeletal-isolated endocrine lesions clarified that these disorders represent a spectrum of phenotypic expressions of the same basic disorder, probably reflecting different patterns of somatic mosaicism [15]. Moreover, GNAS1 mutations are also found in (intramuscular and cellular) myxomas [16] and the cooccurrence of fibrous dysplasia and myxomas is known as Mazabraud syndrome [17]. Interestingly, GNAS1 mutations are found in the cooccurring myxomas as well and are absent in a morphological mimic of myxoma: low-grade myxofibrosarcoma [18]. Finally, inactivating mutations of the hSNF5/INI1 gene are found in rhabdoid tumors. hSNF5 is a core member of the SWI/SNF chromatin remodeling complex and hSNF5 loss leads to epigenetically based changes in transcription resulting in cell cycle progression [19] and genomically stable tumors [20].

Sarcomas with more or less specific amplifications

While in principle not tumor specific, some sarcomas are characterized by a highly reproducible amplification such as in case of atypical lipomatous tumor/ well-differentiated liposarcoma/dedifferentiated liposarcoma the amplification of CDK4 and MDM2 [21-23]. While most if not all of the aforementioned tumors harbor such an amplification and as such it can be used to recognize a lipogenic origin in the dedifferentiated areas of dedifferentiated liposarcoma, it is by no means tumor specific as similar amplifications occur for instance in osteosarcoma or chondrosarcoma [24]. This genetic marker however is in context quite useful for diagnostic purposes.

Sarcomas with nonspecific complex karyotypes

The more frequent sarcomas, like high-grade pleomorphic sarcoma, myxofibrosarcoma [25] or leiomyosarcoma [26], have complex karyotypes lacking specific genetic aberrations. 
For instance, for chondrosarcoma development, a multistep genetic model is presumed. Chondrosarcomas can be either central (arising in the medullar cavity of bone) or peripheral (at the surface of bone). Peripheral chondrosarcomas arise secondarily within the cartilaginous cap of a benign osteochondroma. Osteochondromas can occur within an autosomal dominantly inherited syndrome, Multiple Osteochondromas, in which mutations occur in either EXT1 or EXT2 [27]. These encode glycosyltransferases catalyzing heparan sulphate chain elongation on heparan sulphate proteoglycans, which are important for cellular signaling of Hedgehog, Fibroblast Growth Factor, Wnt, Bone Morphogenetic Protein and Transforming Growth Factor beta. Thus, while it is clear that inactivation of EXT underlies osteochondroma development $[28,29]$, so far, unidentified additional genetic changes are required for malignant transformation towards secondary peripheral chondrosarcoma, resulting in more complex karyotypes including near-haploidy and polyploidization $[30,31]$. In contrast, in the more common central chondrosarcoma EXT is not involved [32]. Instead, complex karyotypes are found especially in high-grade chondrosarcoma [31,33,34], and $96 \%$ of them contains alterations at some level in the pRb pathway [35]. Thus, the genetic background of tumors without specific genetic aberrations is slowly being elucidated.

\section{Classification of sarcomas}

Since soft tissue tumors are relatively rare compared with epithelial malignancies, they are generally regarded difficult by surgical pathologists. Soft tissue tumors constitute a very heterogeneous group of tumors containing $>100$ histological types and subtypes. The considerable morphological overlap between the different diagnostic entities further adds to difficulties in classification [36]. Classification is however essential since these different entities require different treatment strategies and have a different outcome. In classifying tumors, the pathologist can be assisted by immunohistochemistry and molecular diagnostics [37]. Immunohistochemistry is used to confirm the line of differentiation, while molecular techniques can identify specific chromosomal translocations or mutations. The 2002 WHO classification of bone and soft tissue tumors is mainly based on the integration of morphology and genetics [36]. This classification is at present widely accepted and used.

\section{Use of specific molecular changes in differential diagnosis}

The differential diagnosis among the groups of small blue round cell tumors and spindle cell tumors can be very difficult for pathologists due to the high number of entities and their morphological overlap. Although the morphology and immunohistochemistry remain at the cornerstone of the diagnosis, the detection of specific genetic alterations, either translocations or somatic mutations, can be very helpful. Molecular diagnostics is especially important in those cases with unusual morphology, immunohistochemistry or clinical presentation.

The term "small blue round cell" tumor encompasses a heterogeneous group of tumors that share the presence of undifferentiated small round cells with scant cytoplasm at histology. The differential diagnosis includes Ewing sarcoma/PNET, neuroblastoma, non-Hodgkin lymphoma, poorly differentiated (round cell) synovial sarcoma, rhabdomyosarcoma, small cell osteosarcoma, desmoplastic round cell tumor, and mesenchymal chondrosarcoma (Table 1). Due to the absence of distinguishing morphological features, their distinction can be difficult. Using immunohistochemistry and conventional histochemical stainings, many of these entities can already be distinguished. In addition, molecular diagnostics can be used to detect specific reciprocal translocations in Ewing sarcoma, rhabdomyosarcoma, synovial sarcoma or desmoplastic small round cell tumor. Either (Real-Time) PCR [38] on RNA isolated from frozen or paraffin-embedded tumor tissue,or FISH on paraffin-embedded slides can be used to detect these translocations. Especially in case of poorly differentiated synovial sarcoma versus Ewing sarcoma/ PNET the morphology and the immunohistochemical profile can be identical requiring the demonstration of a EWSR1 or SS18 rearrangement to come to a correct diagnosis and therapy.

Spindle cell tumors share, as their name implies, a spindle cell morphology of the tumor cells. The differential diagnosis includes monophasic synovial sarcoma, leiomyosarcoma, solitary fibrous tumor, malignant peripheral nerve sheath tumor, clear cell sarcoma, fibrohistiocytic tumors, dedifferentiated liposarcoma, spindle cell rhabdomyosarcoma, and in abdominal localization, gastrointestinal stromal tumor (Table 2). Monophasic synovial sarcoma and clear cell sarcoma carry specific chromosomal translocations that can be used. This is especially helpful in the distinction of MPNST and monophasic synovial sarcoma, which can be morphologically and immunohistochemically indistinguishable. KIT or PDGFRA mutation analysis can be helpful to diagnose gastrointestinal stromal tumor, especially in the small proportion in which CD117 is negative. The diagnosis of dedifferentiated liposarcoma especially if the well-differentiated liposarcoma component is not present at morphology can be facilitated by demonstrating the $12 \mathrm{q} 13$ amplification that is characteristic for these lesions, either by immunohistochemistry or FISH for amplification of MDM2 [39, 40]. 
Table 1 Distinguishing features in small blue round cell tumors

\begin{tabular}{|c|c|c|c|}
\hline & Histochemical staining & Immunohistochemistry & Molecular diagnostics \\
\hline Ewing sarcoma/PNET & PAS positive & CD99+ & Translocation EWSR1 \\
\hline Neuroblastoma & - & CD99-, CD56+ & MYCN amplification \\
\hline Alveolar rhabdomyosarcoma & - & MYF4 (myogenin)+, Desmin + & $\begin{array}{l}\text { Translocation FKHR } \\
\text { (FOXO1A) }\end{array}$ \\
\hline Non-Hodgkin lymphoma/leukemia & PAS negative & CD45+ & Depending on subtype \\
\hline Small cell carcinoma & - & $\begin{array}{l}\text { Keratin+, neuroendocrine } \\
\text { markers }\end{array}$ & - \\
\hline $\begin{array}{l}\text { (Poorly differentiated) synovial } \\
\text { sarcoma }\end{array}$ & - & $\mathrm{CD} 99+, \mathrm{BCL}-2+$ & Translocation SS18 (SYT) \\
\hline Small cell osteosarcoma & $\begin{array}{l}\text { Deposition of bone } \\
\text { (alkaline phosphatase) }\end{array}$ & - & - \\
\hline Mesenchymal chondrosarcoma & Deposition of cartilage & - & - \\
\hline $\begin{array}{l}\text { Desmoplastic small round } \\
\text { cell tumor }\end{array}$ & - & $\begin{array}{l}\text { Coexpression keratin } \\
\text { and desmin }\end{array}$ & Translocation EWSR1 \\
\hline Melanoma & - & Melanocytic markers + & - \\
\hline
\end{tabular}

\section{Detection of minimal residual disease}

Following exciting results in molecular screening of lymph nodes for micrometastases of colonic cancer and bone marrow for minimal residual disease after lymphoma treatment, efforts have been made to do the same for sarcomas harboring a tumor-specific translocation as for instance Ewing sarcomas [41, 42]. Presence of tumor cells in bone marrow but not in blood was claimed to be associated with adverse prognosis [43], while others showed an increased risk of systemic relapses associated with bone marrow micrometastasis and circulating tumor cells in localized Ewing tumor.[44]. Tumor cells were shown to be present in a subset of stem cell harvests of Ewings sarcoma patients and their persistence following transplantation was claimed to be associated with relapse. Large prospective multinational randomized trials have been designed such as the EuroEwing 99 trial to investigate these questions. Although this trial is now open for 10 years, still, the data are not mature to draw final conclusions with regard to this question, implying that when a difference is present, this should be minimal at best for the individual patient. For alveolar rhabdomyosarcoma, molecular markers have been advocated for early detection of tumor relapses as well as using a reverse transcriptase-polymerase chain reaction method [45].

\section{Prediction of outcome}

Some tumors like Ewing sarcoma or synovial sarcoma may carry individually one of a spectrum of tumor specific cytogenetic or molecular genetic abnormalities. In retrospective studies, it has been claimed that the prognoses for these tumor entities was influenced by the specific molecular-defined translocation type [46-48]. These appeared in these first studies a powerful prognostic indicator and in case of synovial sarcoma even a predictor of the biphasic versus the monophasic subtype. In due course however, based on either prospectively collected cases treated in the context of a clinical trial or large national sarcoma databases, the prognostic value of these subtypes of translocations has been questioned for both tumor types [49-52]. Next to the specific translocations, some sarcomas, especially well documented in Ewing sarcoma, harbor numerical chromosomal abnormalities,

Table 2 Distinguishing features in spindle cell tumors

\begin{tabular}{llll}
\hline & Histochemical stainings & Immunohistochemistry & Molecular diagnostics \\
\hline Monophasic synovial sarcoma & - & EMA+, keratin+ & Translocation SS18 (SYT) \\
Leiomyosarcoma & - & Smooth muscle markers+ & - \\
Solitary fibrous tumor & - & CD34+ & - \\
MPNST & Reticulin staining & S100 protein in a subset of cases & - \\
Clear cell sarcoma & - & Melanocytic markers + & Translocation EWSR1 \\
GIST & - & CD117+, DOG1+ & KIT/PDGFRA mutation \\
Dedifferentiated liposarcoma & - & MDM2, CDK4 over expression & MDM2 amplification \\
\hline
\end{tabular}


deletions of the p16 region or additional point mutations in p53 [53-57]. These abnormalities are most often grossly overlooked when applying an RT-PCR approach just focusing on the known fusion breakpoints. An important role in tumor progression and prognosis has been claimed for these additional, nontumor-specific events. In case of metastatic GIST, the prognosis is highly correlated to the response to tyrosine kinase-inhibiting drugs [58]. While also immunohistochemical phenotypic markers have been studied with potential prognostic impact [59], these failed to show prognostic impact in contrast to clinical [60] and morphological [61] parameters. Here, especially the type of mutation in KIT or PDGFRA appears to have an important impact on response to tyrosine kinase inhibition [62, 63] while additional molecular events superimposed to the original tumor-specific ones like those described earlier for Ewing sarcoma are increasingly more of interest in studying resistance $[64,65]$ and tumor progression [66].

\section{Identification of molecular targets for treatment}

With the identification of some of the specific changes in sarcomas, therapeutic targets were disclosed. The most well-known example is KIT/PDGFRA mutations in gastrointestinal stromal tumors of which the constitutively active signaling and subsequent tumor growth can be inhibited using tyrosine kinase inhibitors such as imatinib (STI571, Gleevec) [67]. Also, specific translocations have revealed targets for therapy. The COL1A1-PDGFB fusion product in dermatofibrosarcoma protuberans signals through the PDGF receptor in an autocrine loop [8], of which the signaling can be blocked using tyrosine kinase inhibitors acting at PDGFR such as imatinib. Imatinib treatment of this superficially located low-grade sarcoma can be beneficial to reduce tumor size in otherwise inoperable tumors.

\section{Conclusion}

Molecular and cytogenetic studies performed over the past decades have been proven to have major impact in identification, classification, and in some cases, prognostication of a large variety of sarcomas. With regard to diagnosis, the use of molecular techniques for an array of tumor entities has found their way into routine clinicopathological practice. Like the treatment of sarcomas, the application of molecular techniques needs to be under strict protocol and in morphological context in order to avoid disastrous mistakes in tumor classification. Here, a need for vigorous (multi) national quality control assessments, centralization not only of treatment but also of (molecular) diagnosis and development of (multi) national guidelines [68-71] is a future view which needs attention of the pathology community as well as health-care decision makers.

Conflict of interest statement We declare that we have no conflicts of interest.

Open Access This article is distributed under the terms of the Creative Commons Attribution Noncommercial License which permits any noncommercial use, distribution, and reproduction in any medium, provided the original author(s) and source are credited.

\section{References}

1. Mitelman F, Johansson B, Mertens F (2007) The impact of translocations and gene fusions on cancer causation. Nat Rev Cancer 7:233-245

2. de Alava E (2007) Molecular pathology in sarcomas. Clin Transl Oncol 9:130-144

3. Fletcher CDM, Unni KK, Mertens F (2002) WHO Classification of tumours. Pathology and genetics of tumours of soft tissue and bone. IARC Press, Lyon

4. Hogendoorn PC, Collin F, Daugaard S et al (2004) Changing concepts in the pathological basis of soft tissue and bone sarcoma treatment. Eur J Cancer 40:1644-1654

5. Mitelman F, Johansson B, Mertens F (2007) The impact of translocations and gene fusions on cancer causation. Nat Rev Cancer 7:233-245

6. Janknecht R (2005) EWS-ETS oncoproteins: the linchpins of Ewing tumors. Gene 363:1-14

7. O'Brien KP, Seroussi E, Dal Cin P et al (1998) Various regions within the alpha-helical domain of the COL1A1 gene are fused to the second exon of the PDGFB gene in dermatofibrosarcomas and giant-cell fibroblastomas. Genes Chromosomes Cancer 23:187193

8. Shimizu A, O'Brien KP, Sjoblom T et al (1999) The dermatofibrosarcoma protuberans-associated collagen type I alpha 1/ platelet-derived growth factor (PDGF) B-chain fusion gene generates a transforming protein that is processed to functional PDGF-BB. Cancer Res 59:3719-3723

9. Oliveira AM, Hsi BL, Weremowicz S et al (2004) USP6 (Tre2) fusion oncogenes in aneurysmal bone cyst. Cancer Res 64:1920-1923

10. Oliveira AM, Perez-Atayde AR, Dal Cin P et al (2005) Aneurysmal bone cyst variant translocations upregulate USP6 transcription by promoter swapping with the ZNF9, COL1A1, TRAP150, and OMD genes. Oncogene 24(21):3419-3426

11. Oliveira AM, Chou MM, Perez-Atayde A et al (2006) Aneurysmal bone cyst: a neoplasm driven by upregulation of the USP6 oncogene. J Clin Oncol 24:e1

12. Masuda-Robens JM, Kutney SN, Qi H et al (2003) The TRE17 oncogene encodes a component of a novel effector pathway for Rho GTPases Cdc42 and Rac1 and stimulates actin remodeling. Mol Cell Biol 23:2151-2161

13. Jin W, Yun C, Hobbie A et al (2007) Cellular transformation and activation of the phosphoinositide-3-kinase-Akt cascade by the ETV6-NTRK3 chimeric tyrosine kinase requires c-Src. Cancer Res 67:3192-3200

14. Dal Cin P, Sciot R, Brys P et al (2000) Recurrent chromosome aberrations in fibrous dysplasia of the bone: a report of the CHAMP study group. CHromosomes and MorPhology. Cancer Genet Cytogenet 122:30-32

15. Bianco P, Riminucci M, Majolagbe A et al (2000) Mutations of the GNAS1 gene, stromal cell dysfunction, and osteomalacic 
changes in non-McCune-Albright fibrous dysplasia of bone. $\mathrm{J}$ Bone Miner Res 15:120-128

16. Okamoto S, Hisaoka M, Ushijima M et al (2000) Activating Gs (alpha) mutation in intramuscular myxomas with and without fibrous dysplasia of bone. Virchows Arch 437:133-137

17. Faivre L, Nivelon-Chevallier A, Kottler ML et al (2001) Mazabraud syndrome in two patients: clinical overlap with McCune-Albright syndrome. Am J Med Genet 99:132-136

18. Willems SM, Mohseny AB, Balog C, Sewrajsing R, Briaire-de Bruijn IH, Knijnenburg J, Cleton-Jansen AM, Sciot R, Fletcher CD, Deelder AM, Szuhai K, Hensbergen PJ, Hogendoorn PCW (2009) Cellular/intramuscular myxoma and grade I myxofibrosarcoma are characterized by distinct genetic alterations and specific composition of their extracellular matrix. J Cell Mol Med 13 (7):1291-1301

19. Isakoff MS, Sansam CG, Tamayo P et al (2005) Inactivation of the Snf5 tumor suppressor stimulates cell cycle progression and cooperates with p53 loss in oncogenic transformation. Proc Natl Acad Sci U S A 102:17745-17750

20. McKenna ES, Sansam CG, Cho YJ et al (2008) Loss of the epigenetic tumor suppressor SNF5 leads to cancer without genomic instability. Mol Cell Biol 28:6223-6233

21. Dei Tos AP, Doglioni C, Piccinin S et al (2000) Coordinated expression and amplification of the MDM2, CDK4, and HMGI-C genes in atypical lipomatous tumours. J Pathol 190:531-536

22. Meis-Kindblom JM, Sjogren H, Kindblom LG et al (2001) Cytogenetic and molecular genetic analyses of liposarcoma and its soft tissue simulators: recognition of new variants and differential diagnosis. Virchows Arch 439:141-151

23. Sandberg AA (2004) Updates on the cytogenetics and molecular genetics of bone and soft tissue tumors: liposarcoma. Cancer Genet Cytogenet 155:1-24

24. Kanoe H, Nakayama T, Murakami H et al (1998) Amplification of the CDK4 gene in sarcomas: tumor specificity and relationship with the RB gene mutation. Anticancer Res 18:2317-2321

25. Willems SM, Debiec-Rychter M, Szuhai K et al (2006) Local recurrence of myxofibrosarcoma is associated with increase in tumour grade and cytogenetic aberrations, suggesting a multistep tumour progression model. Mod Pathol 19:407-416

26. Sreekantaiah C, Davis JR, Sandberg AA (1993) Chromosomal abnormalities in leiomyosarcomas. Am J Surg Pathol 142:293-305

27. Bovée JVMG (2008) Multiple osteochondromas. Orphanet J Rare Dis 3:3

28. Bovée JVMG, Cleton-Jansen AM, Wuyts W et al (1999) EXTmutation analysis and loss of heterozygosity in sporadic and hereditary osteochondromas and secondary chondrosarcomas. Am J Hum Genet 65:689-698

29. Hameetman L, Szuhai K, Yavas A et al (2007) The role of EXT1 in non hereditary osteochondroma: identification of homozygous deletions. J Natl Cancer Inst 99:396-406

30. Bovée JVMG, Cleton-Jansen AM, Kuipers-Dijkshoorn $\mathrm{N}$ et al (1999) Loss of heterozygosity and DNA ploidy point to a diverging genetic mechanism in the origin of peripheral and central chondrosarcoma. Genes Chrom Cancer 26:237-246

31. Hallor KH, Staaf J, Bovée JVMG et al (2009) Genomic Profiling of Chondrosarcoma: Chromosomal Patterns in Central and Peripheral Tumors. Clin Cancer Res 15(8):2685-2694

32. Schrage YM, Hameetman L, Szuhai K et al (2009) Aberrant heparan sulfate proteoglycan localization, despite normal exostosin, in central chondrosarcoma. Am J Pathol 174:979-988

33. Tallini G, Dorfman H, Brys P et al (2002) Correlation between clinicopathological features and karyotype in 100 cartilaginous and chordoid tumours. A report from the chromosomes and morphology (CHAMP) collaborative study group. J Pathol 196:194-203

34. Bovée JVMG, Sciot R, Dal Cin P et al (2001) Chromosome 9 alterations and trisomy 22 in central chondrosarcoma: a cyto- genetic and DNA flow cytometric analysis of chondrosarcoma subtypes. Diagn Mol Pathol 10:228-236

35. Schrage YM, Lam S, Jochemsen AG et al. (2008). Central chondrosarcoma progression is associated with $\mathrm{pRb}$ pathway alterations; CDK4 downregulation and p16 overexpression inhibit cell growth in vitro. J Cell Mol Med

36. World Health Organization Classification of Tumours (2002) Pathology and genetics of tumours of soft tissue and bone. IARC Press, Lyon

37. Graadt van Roggen JF, Bovée JVMG, Morreau J et al (1999) Diagnostic and prognostic implications of the unfolding molecular biology of bone and soft tissue tumours. J Clin Pathol 52:481-489

38. Peter M, Gilbert E, Delattre O (2001) A multiplex real-time PCR assay for the detection of gene fusions observed in solid tumors. Lab Invest 81:905-912

39. Weaver J, Downs-Kelly E, Goldblum JR et al (2008) Fluorescence in situ hybridization for MDM2 gene amplification as a diagnostic tool in lipomatous neoplasms. Mod Path 21:943-949

40. Sirvent N, Coindre JM, Maire G et al (2007) Detection of MDM2CDK4 amplification by fluorescence in situ hybridization in 200 paraffin-embedded tumor samples: utility in diagnosing adipocytic lesions and comparison with immunohistochemistry and real-time PCR. Am J Surg Pathol 31:1476-1489

41. Avigad S, Cohen IJ, Zilberstein J et al (2004) The predictive potential of molecular detection in the nonmetastatic Ewing family of tumors. Cancer 100:1053-1058

42. Fagnou C, Michon J, Peter M et al (1998) Presence of tumor cells in bone marrow but not in blood is associated with adverse prognosis in patients with Ewing's tumor. Societe Francaise d'Oncologie Pediatrique. J Clin Oncol 16:1707-1711

43. Schleiermacher G, Peter M, Oberlin O et al (2003) Increased risk of systemic relapses associated with bone marrow micrometastasis and circulating tumor cells in localized ewing tumor. J Clin Oncol 21:85-91

44. Yaniv I, Cohen IJ, Stein J et al (2004) Tumor cells are present in stem cell harvests of Ewings sarcoma patients and their persistence following transplantation is associated with relapse. Pediatr Blood Cancer 42:404-409

45. Athale UH, Shurtleff SA, Jenkins JJ et al (2001) Use of reverse transcriptase polymerase chain reaction for diagnosis and staging of alveolar rhabdomyosarcoma, Ewing sarcoma family of tumors, and desmoplastic small round cell tumor. J Pediatr Hematol Oncol 23:99-104

46. Ed A, Kawai A, Healy JH et al (1998) EWS-FL11 fusion transcript structure is an independent determinant of prognosis in Ewing's sarcoma. J Clin Oncol 16:1248-1255

47. Kawai A, Woodruff J, Healy JH et al (1998) SYT-SSX gene fusion as a determinant of morphology and prognosis in synovial sarcoma. N Engl J Med 338:153-160

48. Ladanyi M, Antonescu CR, Leung DH et al (2002) Impact of SYT-SSX fusion type on the clinical behavior of synovial sarcoma: a multi-institutional retrospective study of 243 patients. Cancer Res 62:135-140

49. Coindre JM, Pelmus M, Hostein I et al (2003) Should molecular testing be required for diagnosing synovial sarcoma? A prospective study of 204 cases. Cancer 98:2700-2707

50. Guillou L, Benhattar J, Terrier P et al (2003) SYT-SSX fusion type is not a prognostic factor in synovial sarcoma (SS) patients. A multi-institutional study of 182 cases. Mod Path 16:13A

51. Zoubek A, Dockhorn-Dworniczak B, Delattre O et al (1996) Does expression of different EWS chimeric transcripts define clinically distinct risk groups of Ewing tumor patients? J Clin Oncol $14: 1245-1251$

52. Le Deley M-C, Delattre O, Schaefer KL et al. (2009). Impact of EWS-ETS fusion type on disease progression in Ewing's sarcoma / 
peripheral primitive neuroectodermal tumor: prospective results from the cooperative Euro-E.W.I.N.G.99 trial

53. Szuhai K, Ijszenga M, Tanke HJ et al (2006) Molecular cytogenetic characterization of four previously established and two newly established Ewing sarcoma cell lines. Cancer Genet Cytogenet 166:173-179

54. Wei G, Antonescu CR, de Alava E et al (2000) Prognostic impact of INK4A deletion in Ewing sarcoma. Cancer 89:793-799

55. Tsuchiya T, Sekine K, Hinohara S et al (2000) Analysis of the p16INK4, p14ARF, p15, TP53, and MDM2 genes and their prognostic implications in osteosarcoma and Ewing sarcoma. Cancer Genet Cytogenet 120:91-98

56. Ueda Y, Dockhorn-Dworniczak B, Blasius S et al (1993) Analysis of mutant p53 protein in osteosarcomas and other malignant and benign lesions of bone. J Cancer Res Clin Oncol 119:172-178

57. Armengol G, Tarkkanen M, Virolainen M et al (1997) Recurrent gains of 1q, 8 and 12 in the Ewing family of tumours by comparative genomic hybridization. Br J Cancer 75:1403-1409

58. Verweij J, Casali PG, Zalcberg J et al (2004) Progression-free survival in gastrointestinal stromal tumours with high-dose imatinib: randomised trial. Lancet 364:1127-1134

59. Sciot R, Debiec-Rychter M, Daugaard S et al (2008) Distribution and prognostic value of histopathologic data and immunohistochemical markers in gastrointestinal stromal tumours (GISTs): an analysis of the EORTC phase III trial of treatment of metastatic GISTs with imatinib mesylate. Eur J Cancer 44(13):1855-1860

60. Van Glabbeke M, Verweij J, Casali PG et al (2005) Initial and late resistance to imatinib in advanced gastrointestinal stromal tumors are predicted by different prognostic factors: a European organisation for research and treatment of cancer-Italian Sarcoma groupaustralasian gastrointestinal trials group study. J Clin Oncol 23:5795-5804

61. Fletcher CDM, Berman JJ, Corless C et al (2002) Diagnosis of gastrointestinal stromal tumors: a consensus approach. Hum Pathol 33:459-465
62. Heinrich MC, Corless CL, Demetri GD et al (2003) Kinase mutations and imatinib response in patients with metastatic gastrointestinal stromal tumor. J Clin Oncol 21:4342-4349

63. Debiec-Rychter M, Sciot R, Le Cesne A et al (2006) KIT mutations and dose selection for imatinib in patients with advanced gastrointestinal stromal tumours. Eur J Cancer 42:1093-1103

64. Heinrich MC, Corless CL, Blanke CD et al (2006) Molecular correlates of imatinib resistance in gastrointestinal stromal tumors. J Clin Oncol 24:4764-4774

65. Debiec-Rychter M, Cools J, Dumez H et al (2005) Mechanisms of resistance to imatinib mesylate in gastrointestinal stromal tumors and activity of the PKC412 inhibitor against imatinib-resistant mutants. Gastroenterology 128:270-279

66. Romeo S, Diebiec-Rychter M, Van Glabbeke M et al (2009) Cell cycle/apoptosis molecules expression correlates with Imatinib response in patients with advanced gastro-intestinal stromal tumours. Clin Cancer Res 15:4191-4198

67. Corless CL, Heinrich MC (2008) Molecular pathobiology of gastrointestinal stromal sarcomas. Annu Rev Pathol 3:557-586

68. Blay JY, Bonvalot S, Casali P et al (2005) Consensus meeting for the management of gastrointestinal stromal tumors. Report of the GIST consensus conference of 20-21 March 2004, under the auspices of ESMO. Ann Oncol 16:566-578

69. Paulussen M, Bielack S, Jurgens $H$ et al (2008) Ewing's sarcoma of the bone: ESMO clinical recommendations for diagnosis, treatment and follow-up. Ann Oncol 19(Suppl 2):ii97-ii98

70. Bielack S, Carrle D, Jost L (2008) Osteosarcoma: ESMO clinical recommendations for diagnosis, treatment and follow-up. Ann Oncol 19(Suppl 2):ii94-ii96

71. Jansen-Landheer ML, Krijnen P, Oostindier MJ et al (2009) Improved diagnosis and treatment of soft tissue sarcoma patients after implementation of national guidelines: a population-based study. Eur J Surg Oncol. doi:10.1016/j.ejso. 2009.05.002 